\title{
THE SCIENTIFIC AND TECHNICAL SERVICE FUNCTION OF AGRICULTURAL DIGITAL LIBRARY IN COUNTRYSIDE INFORMATIZATION DEVELOPMENT AND CONSTRUCTION UNDER NETWORK ENVIRONMENT
}

\author{
Xichuan Guo \\ The Agricultural Information Institute of the Chinese Academy of Agricultural Sciences, \\ 100081,Beijing P. R. China, Tel: +86-010-82109886call2209,Email: guoxc@caas.net.cn
}

\begin{abstract}
By analyzing internet popularization in rural China and open questions in rural information service, together with service function of agricultural digital library in rural informatization construction, this article makes a study of how to give full play to agricultural digital library's various advantages, in order to make even greater contributions to our country's rural informatization construction.
\end{abstract}

Keywords: agricultural digital library, rural, informatization construction, information service, internet popularization

\section{FOREWORD}

21st century will be an era of information agriculture, computer and information technology will bring profound influence on modernization of traditional speciality. In point of countryside, the old conventional production awareness and agricultural structure have been smashed gradually and replaced by modern agriculture awareness and new pattern of agricultural economy; Ecological agriculture have been attached great importance to; Green food, economic planting, township enterprise and aquaculture have been developing at very fast speed; Township enterprises

Please use the following format when citing this chapter:

Guo, X., 2009, in IFIP International Federation for Information Processing, Volume 294, Computer and Computing Technologies in Agriculture II, Volume 2, eds. D. Li, Z. Chunjiang, (Boston: Springer), pp. 1389-1396. 
are developing gradually towards industrialization, specialization, integration and socialization; A majority of agricultural science and technology workers, farmers, and farmer-enterpriser are seeking zealously for information in order to know the trends and master the skills. . Compared with the applications such as research, industry and trade in our country, the popularization of information technology and internet are relatively hysteretic in agricultural utilization, but as the fast increase of netizens in the rural China area, the implementation of construction of basic network facilities such as "extend to every village" project and "every town sets up their own website " project will hasten the improvement of rural internet environment. . Researches on agriculture informatization's development and how an agricultural digital library can play its role in development and construction of agriculture informatization is a topic worth exploring.

\section{ACTUALITY OF RURAL INTERNET POPULARIZATION IN OUR COUNTRY}

The number of netizens in China had increased rapidly to 210 million up to Dec, 2007. It was 48 million more than that of Jun. 2007, the number is 73 million for the year 2007 and the annual growth rate reached 53.3\%. Namely, in the past year, the average growth of number of netizens is 200 thousand per day. Rural netizens (refer to the netizens dwelling in countryside for the moment ) under swift growth is an importance component of newly increased netizens.. In 2007, the annual growth rate of rural netizens exceeded $100 \%$ and reached $127.7 \%$; the number came up to 52.62 million. Among 7.3 million newly increased netizens, there are 2.917 million from countryside.

The number of rural netizens will keep growing in the future, which will be the major factor of the increase.. There are two reasons: Firstly, China's macroeconomic condition is very good, and will keep developing all along, what's more, the improvement of people's quality of life could be assured. Secondly, operators and service systems from different operators under Ministry of Information Industry (MII) such as "extend to every village" project and "every town has its own website" project would hasten the improvement of internet environmental in countryside, thus accelerate the increase of rural netizens. According to the survey, the utilization of rural netizens, for the moment, are mainly for information, minor for recreation.

The pinch of information in countryside may possibly become an important factor in enlarging the gap between developments of countryside and towns. Due to the geographic problem, the transportation in rural area is relatively inconvenient. Undoubtedly, the internet becomes the most convenient and prompt source to bring information to the area. Farmers 
could get access to advanced technology and information conveniently at a low price, and can obtain required information on planting, breeding and unclosing marketing channel, etc. What's more, the internet can play a great role in management, rural education, and medical treatment and so on. Information provided by internet will promote new socialism countryside construction. .

\section{ANALYSES OF OPEN QUESTION IN INFORMATION SERVICES IN COUNTRYSIDE}

\subsection{Frailty of Farmers' Information cell Consciousness}

In a long time, because of small-scale production, farmers become accustom to listen to their experience on what to plant and what to breed, however, they are lack of awareness of the importance of information and not capable enough to get information.. Meanwhile, due to the restrictions of economic foundation, cultural quality and geographic regions, they don't have the condition to obtain and put out information from and on internet in time. This kind of information consciousness impacts construction of modernization of agriculture. Every year, thousands of agricultural scientific payoffs come into being in our country, But those are converted to be used in agricultural production are only about one third. Network-based digital library, particularly digital library of agricultural colleges and universities can be justified in acting as the information medium and should be functional as information bridges.

\subsection{Agricultural Information Resources Lacks Diversity}

Countryside are always dotty area of economic development, so agricultural book materials, network information resources are lack of diversity.. Although most countryside have founded wireless or cable television network, broadcasting call system, the agricultural information service provided is limited. Actually, useful information on agriculture is very little; Scope of payoff generalization is finite. Our agronomist has quite a lot achievement, but as to vast rural area all over the country, agricultural production is not instructed under science. Utilization of agronomist system not yet draws forth farmers' response. 


\subsection{Issuance of Agricultural Information not Smooth}

To spread agricultural information, grass roots in countryside are by dint of holding a meeting, giving agricultural lecture, reinfusion on wire, cable $\mathrm{TV}$ and so on. Apparently, it can not catch up with the request of turn of the market. Backwardness and passivity of agricultural information dissemination will certainly bring about the hysteresis of agricultural information, which will result in sharp swing of agricultural production, and crop surplus or shortage, and impact agricultural reorganization of an industry's process. According to statistics, information transfer between decentralized management farmer and National Bureau of Statistics will need at least half a month.

\subsection{Lack of Agricultural Information Network Talents}

Vast countryside are lack of compound senior talents who can collect and trim out network agricultural information, who can analyze trend of market, who can answer questions and provide in time precise agricultural products information for agricultural products dealers, who know information technology and is familiar with agro technique.. However, because of they pay little attention to agricultural information network talent, invest little fund, plus imperfect training mechanism, for the moment, useful agricultural information resources has not yet been exploited out, technological element of agricultural economy is little, economic efficiency is low.

\section{CONCEPT OF AGRICULTURAL DIGITAL LIBRARY}

In company with fast development of new techniques such as modern communication network technology, computer technology, highly dense storage technology, in 21st century, people are striding towards a truly information resources sharing frontier - digital library, This has became the best choice of development of world library, which is also the only way for libraries to occupy a "do some things "position on information super highway.

Agricultural digital library is to turn original agricultural book materials into digital storage, to precede format conversion and compression disposal to traditional information like text, image, and sounds and so on, in order to translate them into numerical information, then, to precede storage via computer technology, to precede information transfer by the aid of internet, to realize computer search, to build library holdings which can serve for 
local and remote users to access their OPAC, to inquire conventional nonnumeric information, to provide information service for readers bylibrary digitized foundation spermatic internal service in library and supernetization of connection between systems. Compared with traditional agricultural library, agricultural digital library can not only enable users to get summary of related main body, but also provide more original text information for users, to inquire digital resources inner and outer of libraries.

\section{SERVICE FUNCTION OF AGRICULTURAL DIGITAL LIBRARY IN RURAL INFORMATIZATION CONSTRUCTION}

In company with digitization of books and periodicals and other literary, services of library in high-tech agriculture turn to netization and modernization.To realize modernized service libraries need to make use of computer technology and network communication, to carry out scientific management on library bibliographic information, to enhance service efficiency and quality, to realize information resources sharing, realize robotization as well as to joint track with information super highway.Library digitization radically changed method to collect, store, spread and utilize literature information, reformed its service in high-tech agriculture, established user-oriented service pattern.

\subsection{Intend to Train up Countryside High-tech Agricultural Talents out of Participators and Servants}

As information center, digital library plays an irreplaceable role in hightech agricultural training of qualified personnel. Digital library stockpiles prolific professional literature periodical of varied discipline, all manner of bibliographic information, electronic medium material, By reading, one can widen his visual field, widen his span of knowledge, perfect personal knowledge structure day by day and develop body and mind healthily. 


\subsection{To Provide Individuation Custom-tailor Service for Countryside Agricultural Research Production Personnel}

Individuation customization service refers to custom-tailor interface for selected subscriber according to agricultural research production personnel, search and provide customizing messages meeting the users's demands, at the same time, to protect user's privacy by means of security authentication technology. This is also a major trend for digital library development.Individualization service is an important measure to enhance library service quality, to realize service modernization. Digital library make use of new technique, provide custom-built individualization services for all classes of users with specially designed computer system.Custom-built contents include system resources, system interface and regular or nonscheduled mails about relevant column. System resources include all digital resource in the library, network resources, and service information and so on; system interface then include page style and layouts of customtailored module. They sent latest agricultural scientific information and production information to registered users by email in order to provide them with worthy information in time.Agricultural scientific personnel acquire latest bibliographic information, information resources according to his needs from digital library so that they can get their job going..

\subsection{To provide Interactive Intellectualization Reference Queries Service for Agricultural Research Production Personnel}

Reference queries are to provide required information and support for agricultural research production personnel by librarian or information expert with professional method as much as possible. To retrieve among immense information resources from digital library, traditional idiomatic method is far from possible to solve recall ratio and precision ratio problems. Digitization reference queries is a new kind of service pattern establishing on traditional reference queries and network technique, that is to say, get going reference queries service on the internet by using new network technique and information technology. There are two main patterns

\subsubsection{Email based Digitization Reference Queries Service}

Email-based digitization reference queries service is the most simple and popular pattern. This kind of pattern generally sets Up "reference queries"or similar linkage window on homepage or some webpage of the library. Thus users could send consultation problem to relevant managerial staff by email, 
consultants could send answers to agricultural research production personnel from all over the country by email.

\subsubsection{Digitization Reference Queries Service Based on Real-time Interactive Technology}

The unique feature of this pattern is that agricultural research production personnel and librarian can interlocution in real time, the answer can be transferred immediately, nowadays, more popular methods are chatting room BBS, Network Conference, network call center and so on.Chatting rooms primarily use chatting software, both sides could proceed text pattern consultation, Intercourse and Transfer consultation results. We could get going reference queries service in type of network conference by Network Conference software, set up timed network conference connection between Library and agricultural research production personnel. Both sides could exchange ideas via text, image, and sounds. Take advantage of popular network client call center in electronic commerce, they can provide realtime and cooperation based consulting service for agricultural research production personnel, System can enable consultant to choose one-to-one or one-to-many consulting pattern, both sides could transmit various format files and information in real time. They could also browse webpage and demo operational process together, thus to realize telereference service.

\subsection{To Provide Cooperative Digitization Reference Queries Service for Agricultural Research Production Personnel}

Digital reference queries are now walking towards cooperation pattern based on combo form tone library activityCooperation digital reference queries based on netization join 2 or more libraries up, together provide network reference queries, together shoulder the duty, draw upon each other's strengths, so as to enhance quality of service by a wide margin, to incarnate the pursuit for collaboration and resource sharing for quite some time.In this pattern, 2 or more libraries take advantage of network technique to establish digitization reference queries service collaboration between systems. They are researching on agricultural research production personnel put forward consultation problem according to unified form by consulting service linkage on webpage, and then sent forms to supervisory servicer according to factors like nature of problem. Server will automatically pass them to most suitable cooperation member by email. Then answers will send 
back to library initially accepted problems by supervisory servicer and then to user.

\section{CONCLUSION}

In conclusion, agricultural library should realize that in an era when rural internet grows rapidly in china, they should pay attention to farmers' information requirements to realize supreme social benefit, to perfect agricultural digital library's agricultural information service function through indigenous effort, to strike up scientific agricultural information service system, to foster favorable agricultural information service market with a will, to serve to enhance farmers' scientific and cultural quality, to increase their yield and income, to build socialism new countryside.

\section{REFERENCES}

Chen Ai Min. Wang We Displays the library superiority Completes the countryside information service work. Journal of Library and Information Sciences in Agriculture, 2006, 6:84-86

CHEN Zhang jun. Information Service of the University Library and Rural Community, Journal of Library and Information Sciences In Agriculture, 2004, 10:109-111

CNNIC, 21st China internet development status report 2008

CNNIC, 21st China rural internet development status report 2008

Ma DeXing, Construction of Technology Communication Service System of Digital Agr iculture Platform. Journal of Anhui Agri. Sci. 2007, 35 (2) : 614- 615 